\title{
The association between anti-Müllerian hormone and vitamin 25(OH)D serum levels and polycystic ovarian syndrome in adolescent females
}

Samantha Simpson ${ }^{1}$ (D), David B. Seifer ${ }^{1}$, Veronika Shabanova ${ }^{2}$, Anna Y. Lynn ${ }^{3}$, Catherine Howe ${ }^{1}$, Erin Rowe ${ }^{4}$, Sonia Caprio ${ }^{5}$ and Alla Vash-Margita ${ }^{1 *}$

\begin{abstract}
Background: High anti-Müllerian hormone (AMH) levels and 25-hydroxyvitamin D [25(OH)D] deficiency have been associated with polycystic ovarian syndrome (PCOS) in adult women, and implicated in its pathogenesis. Herein we determined if the level of both $\mathrm{AMH}$ and $25(\mathrm{OH}) \mathrm{D}$ are altered in adolescent females with clinical features of PCOS.

Methods: This is a cross-sectional study utilizing a retrospective chart review of 128 patients aged 12-20 referred to an academic adolescent gynecology and endocrinology clinic for an evaluation of suspected PCOS. Unadjusted comparisons of $\mathrm{AMH}$ and $25(\mathrm{OH}) \mathrm{D}$ distributions between subjects with and without PCOS were performed using the Wilcoxon Rank Sum test. Quantile regression was used to compare the median AMH and 25(OH)D between subject groups; adjusting for race, ethnicity, BMl, insurance type, age, and season when bloodwork was performed.

Results: Seventy-four subjects were classified as having PCOS by meeting $\geq 2$ of the three Rotterdam diagnostic criteria, and 47 subjects met only one Rotterdam diagnostic criteria, and were used as the comparative non-PCOS group. There were statistically significant unadjusted differences in median levels of AMH and 25(OH)D. In the adjusted analyses, median AMH was significantly higher in the PCOS group compared to the non-PCOS group (+ $2.39 \mathrm{ng} / \mathrm{mL}, 95 \% \mathrm{Cl} 0.43,4.35, p=0.018) ; 25(\mathrm{OH}) \mathrm{D}$ was significantly lower in the PCOS group $(-9.01 \mathrm{ng} / \mathrm{mL}, 95 \% \mathrm{Cl}$ $-14.49,-3.53 p=0.001)$. In our sample, adolescents in both groups had insufficient $25(\mathrm{OH}) \mathrm{D}$ level $(22 \mathrm{ng} / \mathrm{mL})$ and elevated BMI $(32.2 \mathrm{~kg} / \mathrm{m} 2)$.

Conclusions: Adolescents with PCOS display high levels of AMH and low 25(OH)D levels. Since traditional clinical markers of PCOS may be physiologic in adolescents, AMH and 25(OH)D may be used as surrogate markers of PCOS risk in adolescents.
\end{abstract}

Keywords: Polycystic ovarian syndrome, Adolescents, Anti-Müllerian hormone, Vitamin D

\footnotetext{
* Correspondence: alla.vash-margita@yale.edu

'Department of Obstetrics, Gynecology, and Reproductive Sciences, Yale School of Medicine, 310 Cedar Street, New Haven, CT 06520-8063, USA

Full list of author information is available at the end of the article
}

(C) The Author(s). 2020 Open Access This article is licensed under a Creative Commons Attribution 4.0 International License, which permits use, sharing, adaptation, distribution and reproduction in any medium or format, as long as you give appropriate credit to the original author(s) and the source, provide a link to the Creative Commons licence, and indicate if changes were made. The images or other third party material in this article are included in the article's Creative Commons licence, unless indicated otherwise in a credit line to the material. If material is not included in the article's Creative Commons licence and your intended use is not permitted by statutory regulation or exceeds the permitted use, you will need to obtain permission directly from the copyright holder. To view a copy of this licence, visit http://creativecommons.org/licenses/by/4.0/ The Creative Commons Public Domain Dedication waiver (http://creativecommons.org/publicdomain/zero/1.0/) applies to the data made available in this article, unless otherwise stated in a credit line to the data. 


\section{Background}

Diagnosis of polycystic ovarian syndrome (PCOS) in the adolescent population remains imprecise. In adults, the Rotterdam criteria - a diagnosis of exclusion in which two of three symptoms must be present, including oligomenorrhea or amenorrhea, clinical or biochemical evidence of hyperandrogenism, and polycystic appearing ovaries - are a commonly used algorithm to determine if a patient meets criteria for the PCOS diagnosis and warrants additional work up and ongoing surveillance for the syndrome's sequelae $[1,2]$. Adolescents may incur the health risks of PCOS, but the adult diagnostic criteria may be difficult to apply to this younger population [3-6]. Adolescents are more likely to have a physiologically long intermenstrual interval which can persist for up to 5 years after menarche due to immaturity of the hypothalamicpituitary axis [6-8]. Adolescents are more likely to have acne, with up to $29.5 \%$ of pubertal girls exhibiting significant inflammatory acne without concomitant differences in testosterone when compared to their acne-less peers [9]. Additionally, there is disagreement about the definition of polycystic-appearing ovaries in the adolescent population. The Rotterdam criteria use ovarian volume greater than $10 \mathrm{~mL}$ or more than 12 follicles on an ovary using a vaginal transducer, however, adolescents have been noted to have greater ovarian volumes and follicular counts than adult women, and it is not recommended to perform vaginal ultrasound on this population $[6,10,11]$. In a retrospective study, only $38 \%$ of adolescents who met Rotterdam criteria for PCOS had ovarian volumes $\geq 10$ $\mathrm{mL}$, while $7 \%$ of a comparison non-PCOS population had ovarian volumes $\geq 10 \mathrm{~mL}$ [12]. In a prospective study, $35 \%$ of an unselected adolescent population had polycystic ovarian appearance [6]. Recent guidelines recommend against using ultrasound at all in adolescents for diagnosis of PCOS until 8 years post-menarche [5]. However, similar to adult women, we know that larger ovaries and higher antral follicle counts in adolescents are associated with elevated androgens [13].

In adult women, it has been noted that women with PCOS tend to have a higher AMH than those without PCOS [14-16]. This is biologically plausible as $\mathrm{AMH}$ is secreted by the granulosa cells of pre-antral and small antral ovarian follicles [17]. It has been suggested that $\mathrm{AMH}$ may be a better determinant of the overabundance of ovarian follicles typical of PCOS than antral follicle count, as ultrasound is dependent on the quality of the ultrasound and the interpreter [18]. Higher AMH levels have been associated with greater menstrual disturbances and greater ovarian volume $[15,19,20]$. Serum AMH cutoffs for PCOS in adults have been proposed, ranging from $3.94 \mathrm{ng} / \mathrm{mL}$ with area under the curve (AUC) of 0.916 and $89.8 \%$ specificity and $80 \%$ sensitivity [21], $4.45 \mathrm{ng} / \mathrm{mL}$ with AUC of 0.870 and $74.6 \%$ specificity and $76.1 \%$ sensitivity [22], to $5.72 \mathrm{ng} / \mathrm{mL}$ with AUC of 0.77 [19]. A meta-analysis settled on an AMH cutoff of $4.7 \mathrm{ng} / \mathrm{mL}$ with AUC 0.87 with specificity of $79.4 \%$ and sensitivity of $82.8 \%$ [23]. In adolescents, the average AMH tends to be higher. Previous studies in adolescents identified a cutoff of $7 \mathrm{ng} / \mathrm{mL}$ with AUC of 0.87 [24], and a cutoff of 6.26 with AUC 0.788 [25]. These studies have been criticized, however, for comparing obese oligomenorrheic girls with thin, normally menstruating counterparts.

Deficiency of 25-hydroxyvitamin D [25(OH)D] has been implicated as a mitigable factor in PCOS symptomatology [26-28]. Supplementation of 25(OH)D has been shown to decrease serum triglycerides, serum androgen levels, liver markers, hirsutism, insulin resistance, and normalize menstrual cycles in adult women with PCOS [26, 29-34]. 25(OH)D insufficiency (20-29 ng/mL) and deficiency (less than $20 \mathrm{ng} / \mathrm{mL}$ ) is defined the same in adolescents and adults [35]. In adolescents, the association between $25(\mathrm{OH}) \mathrm{D}$ deficiency and PCOS is not as straightforward, with some small studies failing to find any connection [36, 37].

Molecularly, AMH and 25(OH)D are related [38-40]. $\mathrm{AMH}$ expression is regulated by $25(\mathrm{OH}) \mathrm{D}$ binding to the vitamin $\mathrm{D}$ receptor site in animals and humans, though the nature of this regulation has not been clearly elucidated $[41,42]$. Studies in human prostate cell lines showed that the promoter region for the $\mathrm{AMH}$ gene contains a 25(OH)D response element [43]. AMH and $25(\mathrm{OH}) \mathrm{D}$ have been studied together clinically in adult women with and without PCOS and no consistent relationship has been found, but these two serum analytes have not been evaluated together in the adolescent population [38, 44, 45]. If we could establish a significant clinical difference in these hormone concentrations between adolescents with PCOS and a comparative group, this would strengthen AMH's ability to be used as a biomarker for PCOS in the diagnostically challenging adolescent population. It would also identify a mitigable analyte, $25(\mathrm{OH}) \mathrm{D}$, which could potentially open new treatment pathways for adolescents with PCOS. In this retrospective cross-sectional study, we aimed to determine if adolescents who met Rotterdam criteria for PCOS had different median levels of $\mathrm{AMH}$ and $25(\mathrm{OH}) \mathrm{D}$, when compared to adolescents who met one aspect of the Rotterdam criteria but did not ultimately meet the current diagnostic standard for PCOS.

\section{Methods}

\section{Study population}

This retrospective study was approved by our institutional review board (Yale University IRB \# 2000024068). We conducted a chart review of serial consecutive patients who were referred to the adolescent gynecology 
and endocrinology clinic (AGEC) for concern for PCOS (presenting complaints of oligomenorrhea, amenorrhea, hirsutism, acne, or elevated androgens) from November 2017 to December 2019. Inclusion criteria were a referral to AGEC, age range $12-20$ years, and being at least 24 months post-menarche [46]. Patients were excluded if their oligomenorrhea was due to continuous hormonal contraceptives (such as medroxyprogesterone acetate intramuscular injections or continuous combined hormonal pills), if they had overt thyroid dysfunction or abnormal prolactin values, or had other causes of hyperandrogenism such as congenital adrenal hyperplasia or adrenal or ovarian tumor (evaluated via 17hydroxyprogesterone value and the pelvic ultrasound in patients with elevated testosterone, or adrenal $\mathrm{CT}$ in patients with elevated serum DHEA-S).

\section{Data collection}

For each eligible patient, we abstracted data from their clinical evaluation, which included a complete medical history, physical exam (though not necessarily a gynecologic exam), bloodwork according to the patient's presenting symptom, and transabdominal pelvic ultrasound at the discretion of the attending physician. All subjects included in this retrospective chart review had relevant laboratory work and their transabdominal ultrasound performed within 6 months of their initial visit, before treatment for PCOS was initiated. Demographic variables extracted from the medical records were age, race, ethnicity, and insurance type. Clinical and medical variables were body mass index (BMI), age at menarche, presence of acne or hirsutism, levels of hormones, season of 25(OH)D bloodwork, and transabdominal ultrasound measurements of right and left ovaries.

\section{Laboratory assays}

Due to the retrospective nature of this review, there was some heterogeneity in methods of laboratory assay. Quantification of 25(OH)D (one of two primary outcomes) was performed by liquid chromatographytandem mass spectrometry (reference range 5.2-311 ng/ $\mathrm{mL}$, intra-assay coefficients of variance $(\mathrm{CoV}) 3.9-6.9 \%$, inter-assay $\mathrm{CoV}$ 7.2\%) [47] and by immunoassay (reference range $4-150 \mathrm{ng} / \mathrm{mL}$, intra-assay $\mathrm{CoV} 2.3-5.4 \%$, inter-assay CoV 7.8-10.6\%) (DiaSorin; Saluggia, Italy); for both, laboratory standards considered values $<30 \mathrm{ng} /$ $\mathrm{dL}$ evidence of $25(\mathrm{OH}) \mathrm{D}$ deficiency. AMH (one of two primary outcomes) was quantified by chemiluminescent immunoassay (reference range $0.08-24 \mathrm{ng} / \mathrm{mL}$, intraassay $\mathrm{CoV} 1.8-2.3 \%$, inter-assay $\mathrm{CoV} 0.9-4.4 \%$ ) (Beckman-Coulter; Brea, CA). Androstenedione was quantified by chromatography / mass spectrometry. DHEA and DHEA-S were quantified by immunoassay. Total testosterone was measured by competitive chemiluminescent immunoassay, and free testosterone was calculated based on measured total testosterone and measured sex hormone binding globulin. AMH is routinely ordered on adolescent females presenting for PCOS evaluation at our clinic, and $25(\mathrm{OH}) \mathrm{D}$ is routinely ordered in all overweight adolescents, as our clinic is in the Northern United States and there is a high prevalence of vitamin D deficiency and insufficiency.

\section{Ultrasound interpretation}

All available ultrasound images done as part of the patient's workup were re-interpreted by a single blinded university-affiliated pediatric radiologist who remeasured ovarian volume $(0.5 \mathrm{x}$ length $\mathrm{x}$ width $\mathrm{x}$ thickness) [48] and assessed if follicles $(2-9 \mathrm{~mm})$ were peripherally distributed or not. Due to lack of real-time imaging, the radiologist was unable to assess total number of follicles. Ovaries were considered polycystic appearing if follicles were peripherally distributed and one or both ovaries had a volume $\geq 10 \mathrm{~mL}$.

\section{Comparator group assignment}

Patients were classified as having PCOS if they met two or three of the Rotterdam criteria (oligomenorrhea or amenorrhea, hyperandrogenism, or polycystic-appearing ovaries) [1] and those who met only one of the Rotterdam criteria were considered as a comparator group, called non-PCOS in this manuscript. This clinical approach has been previously described by other PCOS researchers [49]. The oligomenorrhea / amenorrhea criterion was met if the intermenstrual interval was $>35$ days for a year, or if the subject did not menstruate $>6$ months if she previously had menstruated. Hyperandrogenism criterion was fulfilled if the patient had moderate to severe hirsutism, moderate to severe inflammatory facial or body acne, or total testosterone $>40 \mathrm{ng} / \mathrm{dL}$, free testosterone $>3.6 \mathrm{pg} / \mathrm{mL}$, or dehydroepiandrosteronesulfate (DHEA-S) $>430 \mu \mathrm{g} / \mathrm{dL}$. Polycystic appearing ovaries determined by the independent blinded radiologist as described above.

\section{Analysis}

For the unadjusted analysis, demographic information, clinical findings, and laboratory values between group comparisons were made with Chi-square for categorical variables and Wilcoxon Rank-Sum tests for continuous and scale variables.

Adjusted analysis of the median levels in each primary outcome of interest (AMH and 25(OH)D) was performed using quantile regression, with PCOS diagnosis as the primary predictor, adjusting for race and ethnicity, private insurance status, BMI, age at evaluation, and season of 25(OH)D bloodwork. The adjustments were done with clinically meaningful variables, no matter their 
statistical significance, but we noted associations at alpha of 0.15 . Results from the adjusted analysis were summarized using the effect size, the between-group difference in median levels of primary outcomes, with $95 \%$ confidence intervals (CI) obtained using the percentile method (2.5th and 97.5th percentiles) from 500 bootstrapped samples. The null hypothesis of no association between group (PCOS vs. non-PCOS) and each primary outcome was tested at the two-sided alpha of 0.05. No adjustment for multiple comparisons was done, as these were two different hypotheses. Analyses were formed using SAS 9.4 (Cary, NC).

\section{Results}

\section{Study population}

Out of 128 patients who were referred to AGEC with concern for PCOS, 7 patients presented within 2 years of menarche and were excluded [46]. After evaluation, 74 patients $(61.2 \%)$ were found to meet two or three of the three Rotterdam criteria (PCOS group), and 47 (38.8\%) were found to only meet one criterion (non-PCOS group) (Fig. 1). Of these patients, 59 (79.7\%) in the PCOS group and $38(80.9 \%)$ in the non-PCOS group had 25(OH)D testing; $52(71.3 \%)$ in the PCOS and $23(48.9 \%)$ in the non-PCOS group had AMH testing (Fig. 1). Patient demographic information was compared between the PCOS and non-PCOS groups as a whole, and between patients who had AMH and 25(OH)D results and those who did not, to check for systematic selection bias due to missing data in the primary outcomes (Table 1). In the demographic factors, the only important difference was in the PCOS versus non-PCOS group in the percent of patients reporting oligomenorrhea, which was expected, as this alone is one of the diagnostic criteria for PCOS.

\section{Unadjusted analysis}

Compared to adolescents in the non-PCOS group, median AMH was higher in the PCOS group $(6.7 \mathrm{ng} /$ $\mathrm{mL}$ v $3.6 \mathrm{ng} / \mathrm{mL}, p<0.001)$, while median $25(\mathrm{OH}) \mathrm{D}$ was lower in the PCOS group $(21 \mathrm{ng} / \mathrm{mL}$ v $25 \mathrm{ng} / \mathrm{mL}$, $p=0.049$ ) (Fig. 2). Of the 121 patients in the study, 91 (75.2\%) completed ultrasound evaluation with images that were available for review by the independent blinded radiologist. There were no differences in mean right and left ovarian volumes between the PCOS and non-PCOS groups, but more patients in the PCOS group had peripherally distributed follicles (Table 2).

Total and free testosterone was available in 112 (92.6\%) patients. Patients with PCOS had higher median total $(47.5 \mathrm{ng} / \mathrm{dL}$ v $33 \mathrm{ng} / \mathrm{dL}, p<0.001)$ and free $(7.2 \mathrm{pg} /$ $\mathrm{mL}$ v $4.7 \mathrm{pg} / \mathrm{mL}, \mathrm{p}<0.001)$ testosterone, and higher median 17-hydroxyprogesterone (57 ng/dL v $45 \mathrm{ng} / \mathrm{dL}, p=$ 0.05). Androstenedione, luteinizing hormone, follicle stimulating hormone, and sex hormone binding globulin were comparable between the two groups of patients (Table 2).

\section{Adjusted analysis}

Differences in median levels of both AMH and 25(OH)D persisted in the adjusted models (Table 3). Adolescents with PCOS had significantly lower median levels of 25(OH)D (- 9.01, 95\%CI $-14.49,-3.53)$, but significantly higher median levels of AMH $(2.39,95 \%$ CI $0.43,4.35)$. Of interest, a few statistical trends were noted: Latina subjects had lower median levels of both AMH and 25(OH)D; higher BMI was associated with lower median $\mathrm{AMH}$; and median levels of $25(\mathrm{OH}) \mathrm{D}$ tended to be higher during the summer.

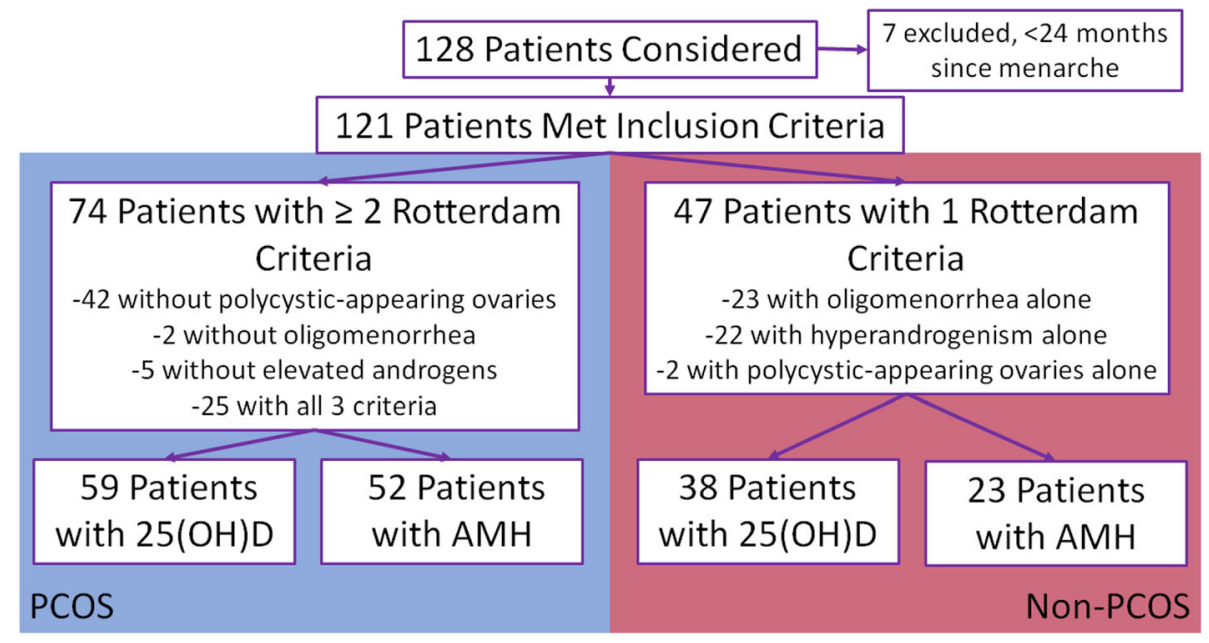

Fig. 1 Consort diagram of patients included in analyses 
Table 1 Demographic information by PCOS status, AMH status, and 25(OH)D status

\begin{tabular}{|c|c|c|c|c|c|c|c|c|c|}
\hline & $\begin{array}{l}\text { PCOS }(n= \\
74)\end{array}$ & $\begin{array}{l}\text { Non-PCOS }(n= \\
\text { 47) }\end{array}$ & $P$ & $\begin{array}{l}\text { AMH }(n= \\
75)\end{array}$ & $\begin{array}{l}\text { No AMH }(n= \\
46)\end{array}$ & $P$ & $\begin{array}{l}25(\mathrm{OH}) \mathrm{D}(n= \\
97)\end{array}$ & $\begin{array}{l}\text { No } 25(\mathrm{OH}) \mathrm{D}(n= \\
24)\end{array}$ & $P$ \\
\hline Age at Evaluation & $16.1 \pm 1.8$ & $15.7 \pm 1.4$ & 0.17 & $15.9 \pm 1.6$ & $16.0 \pm 1.7$ & 0.68 & $15.9 \pm 1.7$ & $16 \pm 1.6$ & 0.74 \\
\hline Age at Menarche & $11.5 \pm 1.8$ & $11.1 \pm 1.5$ & 0.21 & $11.3 \pm 1.6$ & $11.5 \pm 1.8$ & 0.55 & $11.3 \pm 1.7$ & $11.5 \pm 1.6$ & 0.76 \\
\hline $\mathrm{BMI}$ & $31.9 \pm 8.1$ & $32.6 \pm 11.1$ & 0.72 & $31.3 \pm 9.6$ & $33.6 \pm 8.9$ & 0.18 & $32.6 \pm 9.4$ & $30.2 \pm 9$ & 0.26 \\
\hline \multicolumn{10}{|l|}{ Race } \\
\hline Caucasian & 31 (42\%) & $20(43 \%)$ & 0.73 & $29(39 \%)$ & $22(48 \%)$ & 0.64 & $40(41 \%)$ & $11(46 \%)$ & 0.67 \\
\hline Black & $11(15 \%)$ & 9 (20\%) & & $10(13 \%)$ & $10(22 \%)$ & & $14(15 \%)$ & $6(25 \%)$ & \\
\hline Other/No Answer & $32(43 \%)$ & $18(37 \%)$ & & $36(48 \%)$ & $14(30 \%)$ & & $43(44 \%)$ & $7(29 \%)$ & \\
\hline \multicolumn{10}{|l|}{ Ethnicity } \\
\hline Latina & 19 (26\%) & 15 (32\%) & 0.61 & $18(24 \%)$ & $16(35 \%)$ & 0.43 & $28(29 \%)$ & $6(25 \%)$ & 0.49 \\
\hline Not Latina & 44 (59\%) & $28(60 \%)$ & & 44 (59\%) & $28(61 \%)$ & & 55 (57\%) & 17 (71\%) & \\
\hline No Answer & $11(15 \%)$ & $4(8 \%)$ & & 13 (17\%) & $2(4 \%)$ & & $14(14 \%)$ & $1(4 \%)$ & \\
\hline $\begin{array}{l}\text { Oligomenorrhea/ } \\
\text { Amenorrhea }\end{array}$ & 72 (97\%) & $23(49 \%)$ & $\begin{array}{l}< \\
0.001\end{array}$ & 61 (81\%) & $34(74 \%)$ & 0.45 & 76 (78\%) & 19 (79\%) & 0.99 \\
\hline Acne & 32 (43\%) & $12(26 \%)$ & 0.17 & $30(40 \%)$ & $14(30 \%)$ & 0.9 & 35 (36\%) & $9(38 \%)$ & 0.8 \\
\hline Hirsutism & $37(50 \%)$ & $15(32 \%)$ & 0.1 & $34(45 \%)$ & 18 (39\%) & 0.71 & $42(43 \%)$ & $10(42 \%)$ & 0.79 \\
\hline Private Insurance & 31 (42\%) & 19 (40\%) & 0.97 & $32(43 \%)$ & 18 (39\%) & 0.59 & 38 (39\%) & $12(50 \%)$ & 0.44 \\
\hline
\end{tabular}

Values given as Mean \pm Standard Deviation, or Number (Percent). Age in years, BMl in kg/m²

\section{Discussion and conclusions}

To our knowledge, this is the first retrospective study to evaluate levels of AMH and vitamin 25(OH)D in an adolescent cohort concomitantly. We have identified that AMH is significantly higher in adolescent females with PCOS $(6.7 \mathrm{ng} / \mathrm{mL}$ v $3.6 \mathrm{ng} / \mathrm{mL})$, and our values are consistent with previously published reports that suggest AMH "cutoffs" around $6.26-7 \mathrm{ng} / \mathrm{mL}[24,25]$. The prior studies used thin, normally menstruating adolescents as a comparator group to the PCOS population and there was concern that AMH would not be able to be used to actually discriminate the diagnosis of PCOS in a "real world" application. In our study, we used a robust comparator population - these were not healthy adolescents without complaints related to their reproductive health; these were girls with one clinical or biochemical marker used in the diagnosis of PCOS. As the most recent guidelines recommend against the use of the ultrasound criterion in adolescents until 8 years post-menarche [5], adolescents who are at risk for PCOS may benefit from evaluation of AMH as a non-invasive marker for PCOS. This has biologic plausibility as AMH serves as a surrogate marker of ovarian follicle overabundance, and providers would not rely on the skill of the ultrasonographer performing a transabdominal ultrasound in an increasingly obese adolescent PCOS population [18].

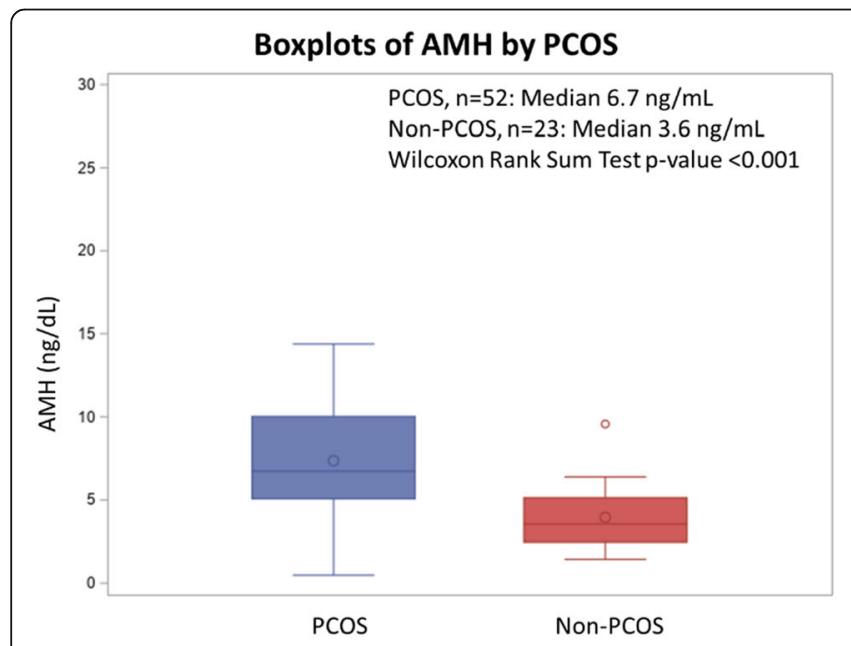

Fig. 2 Boxplots of AMH and 25(OH)D based on PCOS status

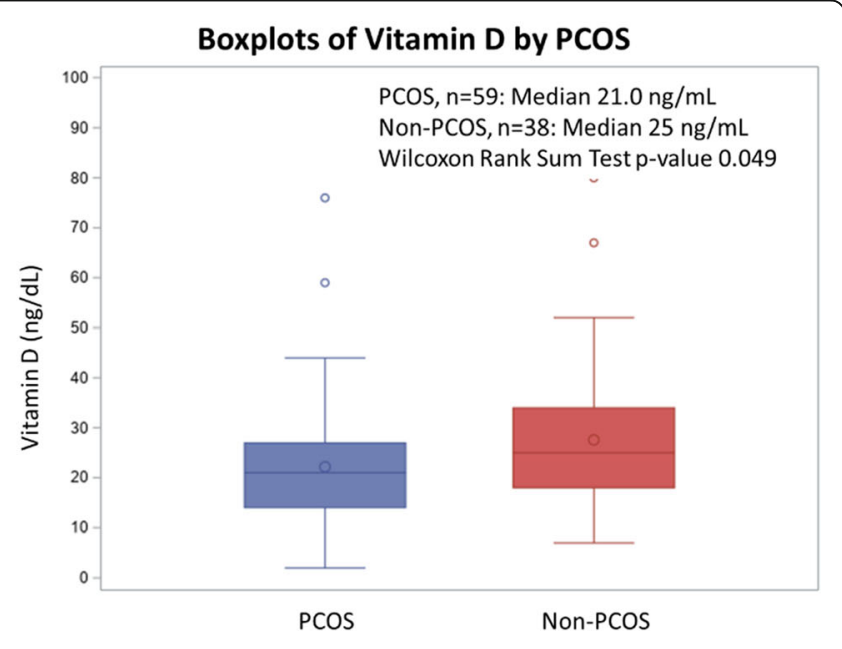


Table 2 Unadjusted analysis

\begin{tabular}{|c|c|c|c|c|c|}
\hline & PCOS & $\mathrm{n}$ & Not PCOS & $\mathbf{n}$ & $P$ \\
\hline $\mathrm{AMH}-\mathrm{ng} / \mathrm{dL}$ & $6.7(0.5-14.4)$ & 52 & $3.6(1.4-9.6)$ & 23 & $<0.001$ \\
\hline $25(\mathrm{OH}) \mathrm{D}-\mathrm{ng} / \mathrm{mL}$ & $21(2-76)$ & 59 & $25(7-80)$ & 38 & 0.049 \\
\hline Testosterone, Total - ng/dL & $47.5(5.2-133)$ & 70 & $33(8.0-118.0)$ & 42 & $<0.001$ \\
\hline Testosterone, Free - pg/dL & $7.2(1.6-24.4)$ & 68 & $4.7(1.4-24.3)$ & 41 & $<0.001$ \\
\hline DHEA-S - $\mu \mathrm{g} / \mathrm{dL}$ & $243(46-869)$ & 64 & $235(86-697)$ & 36 & 0.38 \\
\hline 17-Hydroxyprogesterone - ng/dL & $57(8-261)$ & 51 & $45(4-187)$ & 29 & 0.05 \\
\hline Ovarian Volume - Right, cc & $9.2 \pm 4.4$ & 57 & $10.3 \pm 15.1$ & 34 & 0.69 \\
\hline Ovarian Volume - Left, cc & $16.2 \pm 51.1$ & 56 & $12.5 \pm 28.1$ & 34 & 0.66 \\
\hline Peripheral Follicle Distribution? & $17(23 \%)$ & & $4(8.5 \%)$ & & 0.045 \\
\hline Luteinizing Hormone - IU/L & $11.5(1.8-46.6)$ & 50 & $9.5(1.6-28.1)$ & 17 & 0.34 \\
\hline Follicle Stimulating Hormone - IU/L & $5.7(2.5-11.1)$ & 51 & $5.2(1.3-7.9)$ & 17 & 0.3 \\
\hline
\end{tabular}

Clinical parameters given as Mean \pm Standard Deviation or Number (Percent). Laboratory Values given as Median (Range)

We have also identified lower 25(OH)D concentration in adolescent girls with PCOS. This association was confirmed in the adjusted analysis when taking into account the season during which serum 25(OH)D was collected, as well as age, BMI, ethnicity, race, and insurance status. By demonstrating the clinically meaningful and statistically different lower serum 25(OH)D (by $9 \mathrm{ng} / \mathrm{mL}$ ) in patients with PCOS, we may have identified a mitigable factor that could be increased with consumption of vitamin D-rich foods, exposure to sunlight, or with supplementation of vitamin $\mathrm{D}$, thus leading to improved symptomatology associated with PCOS. Studies in adult women demonstrated positive effects of $25(\mathrm{OH}) \mathrm{D}$ supplementation on biochemical and clinical parameters of PCOS [29-31].

As expected, we found that in in the PCOS group various serum androgens were elevated, the prevalence of oligomenorrhea was increased, and ovarian appearance was with more peripherally distributed follicles compared to the non-PCOS subjects. Our adolescent Latina patients had lower AMH in the adjusted analysis, which was consistent with previous reports in adult women [50, 51], though prior studies have questioned the clinical significance of this in regard to increased risk of early menopause for Latinas [52, 53]. Additionally, 25(OH)D was lower in Latina adolescents with PCOS, albeit not reaching the null hypothesis rejection threshhold. Further research is needed to determine if establishing different $\mathrm{AMH}$ and $25(\mathrm{OH}) \mathrm{D}$ cutoffs for the diagnosis of PCOS in Latina adolescents would be required.

Our study limitations include its retrospective nature of data collection, a convenience sample of subjects from a single center, and incomplete data. For the latter, we

Table 3 Adjusted analysis with quantile regression

\begin{tabular}{|c|c|c|c|c|}
\hline & Adjusted Difference in Median of $A M H$ & $P$ & Adjusted Difference in Median of $25(\mathrm{OH}) \mathrm{D}$ & $P$ \\
\hline PCOS & $2.39(95 \% \mathrm{Cl} 0.43,4.35)$ & 0.018 & $-9.01(95 \% \mathrm{Cl}-14.49,-3.53)$ & 0.001 \\
\hline Age at Evaluation & $-0.37(95 \% \mathrm{Cl}-1.01,0.26)$ & 0.24 & $1.82(95 \% \mathrm{Cl}-0.49,4.13)$ & 0.12 \\
\hline BMI & $-0.11(95 \% \mathrm{Cl}-0.22,0.003)$ & 0.06 & $0.02(95 \% \mathrm{Cl}-0.31,0.35)$ & 0.9 \\
\hline \multicolumn{5}{|l|}{ Race (Black Reference) } \\
\hline Caucasian & $-0.89(95 \% \mathrm{Cl}-4.50,2.73)$ & 0.62 & $5.02(95 \% \mathrm{Cl}-7.14,17.17)$ & 0.41 \\
\hline Other/No Answer & $3.59(95 \% \mathrm{Cl}-0.18,7.36)$ & 0.06 & $2.61(95 \% \mathrm{Cl}-9.82,15.04)$ & 0.68 \\
\hline \multicolumn{5}{|l|}{ Ethnicity (Latina Reference) } \\
\hline Not Latina & $3.83(95 \% \mathrm{Cl} 0.76,6.90)$ & 0.016 & $9.56(95 \% \mathrm{Cl}-0.37,19.49)$ & 0.059 \\
\hline No Private Insurance & $0.81(95 \% \mathrm{Cl}-1.58,3.21)$ & 0.5 & $-0.25(95 \% \mathrm{Cl}-7.40,6.89)$ & 0.94 \\
\hline 25(OH)D Season (Summer Ref) & - & - & & \\
\hline Winter & & & $-14.20(95 \% \mathrm{Cl}-30.47,2.07)$ & 0.086 \\
\hline Fall & & & $-13.02(95 \% \mathrm{Cl}-29.14,3.10)$ & 0.112 \\
\hline Spring & & & $-9.92(95 \% \mathrm{Cl}-27.47,7.63)$ & 0.09 \\
\hline
\end{tabular}

Values given as Median Difference $(95 \% \mathrm{Cl})$ 
compared subjects with and without missing observations, and did not observe systematic differences with respect to important demographic and clinical characteristics. While we did not specifically power our study to examine other risk factors for PCOS, the strength of this study is that it is the largest comparison of AMH and 25(OH)D in adolescent girls with PCOS to date. This study included a typical PCOS population and a comparator group composed of adolescent girls at risk for PCOS. Past studies have used control groups of healthy girls with regular menses and no hyperandrogenism $[37,54]$, or obese girls with regular menses and no hyperandrogenism [25], neither a good comparison to their PCOS counterparts due to potentially severe imbalance in confounders.

Future directions of work may include re-consideration of AMH's use as a potential biomarker for PCOS in adolescents. Since there is such homogeneity in the findings of a discriminatory AMH level to identify PCOS in adolescents using various comparator groups, a meta-analysis of adolescent studies may identify a specific AMH cutoff. The most recent international guidelines for the adolescent population preclude use of ultrasound to diagnose PCOS for 8 years after menarche [5], however the diagnosis of PCOS and workup for the sequelae of the disease cannot wait 8 years - this may put these girls at increased risk of fertility issues, hypertension, diabetes, hyperlipidemia, and endometrial cancer $[3,4,55]$. Serum AMH would therefore be a non-invasive test with biologic plausibility to act a surrogate marker of ovarian follicle overabundance expressed in adolescents with PCOS. More research, such as an adequately powered randomized placebo-controlled clinical trial, needs to be done to properly evaluate the effect of $25(\mathrm{OH}) \mathrm{D}$ supplementation on mitigation and resolution of PCOS-associated signs, symptoms, and aberrant laboratory values in adolescents. In such a trial, AMH may play a unique role as a marker of PCOS as well as of the progress of treatment.

\section{Abbreviations \\ 25(OH)D: 25-hydroxyvitamin D; AGEC: Adolescent gynecology and endocrinology clinic; AMH: Anti-Müllerian hormone; AUC: Area under the curve; BMI: Body-mass index; Cl: Confidence interval; DHEA- \\ S: Dehydroepiandrosterone-sulfate; IRB: Institutional Review Board; \\ PCOS: Polycystic ovarian syndrome}

\section{Acknowledgments}

This work was accepted for oral presentation at the 2020 North American Society for Pediatric and Adolescent Gynecology Annual Clinic and Research Meeting, and was presented virtually on 20 June, 2020.

\section{Authors' contributions}

SS, DS, SC, AVM made substantial contributions to the conception and design of this research. SS, CH, AYL, ER and VS acquired, analyzed, and interpreted data. SS, DS, VS, and AVM drafted and revised this manuscript. All authors approved the submitted version and agree to be personally accountable for their contributions, and ensure that questions related to the accuracy or integrity of the work are appropriately investigated and the resolution is documented in the literature. No editorial services were used in creation of this document, and no changes in authorship since the inception of the work have been made.

\section{Funding}

No funding was involved with this study.

\section{Availability of data and materials}

The datasets used and/or analysed during the current study are available from the corresponding author on reasonable request.

\section{Ethics approval and consent to participate}

This retrospective study was approved by our institutional review board (Yale University IRB \# 2000024068).

\section{Consent for publication}

Not applicable.

\section{Competing interests}

The authors declare that they have no competing interests.

\section{Author details}

${ }^{1}$ Department of Obstetrics, Gynecology, and Reproductive Sciences, Yale School of Medicine, 310 Cedar Street, New Haven, CT 06520-8063, USA. ${ }^{2}$ Department of Biostatistics, Yale School of Public Health, New Haven, CT, USA. ${ }^{3}$ Yale School of Medicine, New Haven, CT, USA. ${ }^{4}$ Department of Radiology and Biomedical Imaging, Yale School of Medicine, New Haven, CT, USA. ${ }^{5}$ Department of Pediatric Endocrinology and Diabetes, Yale School of Medicine, New Haven, CT, USA.

Received: 10 August 2020 Accepted: 13 November 2020

Published online: 21 November 2020

\section{References}

1. Rotterdam ESHRE/ASRM-Sponsored PCOS Consensus Workshop Group. Revised 2003 consensus on diagnostic criteria and long-term health risks related to polycystic ovary syndrome. Fertil Steril. 2003;81:19-25.

2. The American College of Obstetricians and Gynecologists. Polycystic ovary syndrome practice bulletin number 194, 2018.

3. Apter D. Endocrine and metabolic abnormalities in adolescents with PCOSlike condition: consequences for adult reproduction. Trends Endocrinol Metabol. 1998:9:58-61.

4. Witchel SF, Oberfield S, Rosenfield RL, Codner E, Bonny A, Ibáñez L, Pena A, Horikawa R, Gomez-Lobo V, Joel D, Tfayli H, Arslanian S, Dabadghao P, Garcia Rudaz C, Lee PA. The diagnosis of polycystic ovary syndrome during adolescence. Horm Res Paediatr. 2015;83:376-89.

5. Teede H, Misso M, Costello M, Dokras A, Laven J, Moran L, Piltonen T, Norman R. International evidence-based guideline for the assessment and management of polycystic ovary syndrome. Melbourne; 2018.

6. Hickey M, Doherty DA, Atkinson H, Sloboda DM, Franks S, Norman RJ, Hart R. Clinical, ultrasound, and biochemical features of polycystic ovary syndrome in adolescents: implications for diagnosis. Hum Reprod. 2011;26: 1469-77.

7. Apter D, Vihko R. Hormonal patterns of the first menstrual cycles. In: Venturoli S, Flamigni C, Givens JR, editors. Adolescence in females. Chicago: Year Book Medical Publishers; 1985. p. 215-38.

8. Metcalf MG, Skidmore DS, Lowry GF, Mackenzie JA. Incidence of ovulation in the years after the menarche. J Endocrinol. 1983;97:213-9.

9. Lucky AW, Biro FM, Huster GA, Leach AD, Morrison JA, Ratterman J. Acne vulgaris in premenarchal girls. An early sign of puberty associated with rising levels of dehydroepiandosterone. Arch Dermatol. 1994;3:308-14.

10. Senaldi L, Gopi RP, Milla S, Shah B. Is ultrasound useful in the diagnosis of adolescents with polycystic ovary syndrome? J Pediatr Endocr Met. 2015;28: 605-12.

11. Merino PM, Villarroel C, Jesam C, López P, Codner E. New diagnostic criteria of polycystic ovarian morphology for adolescents: impact on prevalence and hormonal profile. Horm Res Paediatr. 2017;88(6):401-7.

12. Youngster M, Ward VL, Blood EA, Barnewolt CE, Emans SJ, Divasta AD. Utility of ultrasound in the diagnosis of polycystic ovary syndrome in adolescents. Fertil Steril. 2014;102:1432-8.

13. Rackow BW, Brink HV, Hammers L, Flannery CA, Lujan ME, Burgert TS. Ovarian morphology by transabdominal ultrasound correlates with 
reproductive and metabolic disturbance in adolescents with PCOS. Adolesc Health. 2018;62:288-93.

14. Tal R, Seifer DB, Khanimov M, Malter HE, Grazi RV, Leader B. Characterization of women with elevated antimullerian hormone levels (AMH): correlation of $\mathrm{AMH}$ with polycystic ovarian syndrome phenotypes and assisted reproductive technology outcome. Am J Obstet Gynecol. 2014:211:e1-8.

15. Matsuzaki T, Munkhzaya M, Iwasa T, Tungalagsuvd A, Yano K, Mayila Y, Yanagihara R, Tokui T, Kato T, Kuwahara A, Matsui S, Irahara M. Relationship between serum anti-mullerian hormone and clinical parameters in polycystic ovary syndrome. Endocr J. 2017;64:531-41.

16. Sir-Petermann T, King NC. Polycystic ovary syndrome: a focus on antiMullerian hormone levels. Expert Rev Endocrinol Metab. 2007;2(6):751-8.

17. Durlinger AL, Visser JA, Themmen AP. Regulation of ovarian function: the role of anti-Müllerian hormone. Reproduction. 2002;124:601-9.

18. Teede H, Misso M, Tassone EC, Dewailly D, Ng EH, Azziz R, Norman RJ, Andersen M, Franks S, Hoeger K, Hutchison S, Oberfield S, Shah D, Hohmann F, Ottey S, Dabadghao LJSE. Anti-Müllerian hormone in PCOS: a review informing international guidelines. Trends Endocrinol Metabol. 2019; 30:467-78.

19. Abbara A, Eng PC, Phylactou M, Clarke SA, Hunjan T, Roberts R, Vimalesvaran S, Christophoulos G, Islam R, Purugganan K, Comninos AN, Trew GH, Salim R, Hramyka A, Owens L, Kelsey T, Dhillo WS. Anti-Mullerian hormone $(\mathrm{AMH})$ in the diagnosis of menstrual disturbance due to polycystic ovarian syndrome. Front Endocrinol. 2019;10:1-11.

20. Dursun F, Güven A, Yildiz M. Assessment of anti-Müllerian hormone levels in management of adolescents with polycystic ovary syndrome. J Clin Res Pediatr Endocrinol. 2016:8:55-60.

21. Sahmay S, Atakul N, Aydogan B, Aydin Y, Imamoglu M, Seyisoglu H. Elevated serum levels of anti-Müllerian hormone can be introduced as a new diagnostic marker for polycystic ovary syndrome. Acta Obstet Gynecol. 2013;92:1369-74.

22. Wiweko B, Maidarti M, Priangga MD, Shafira N, Fernando D, Sumapraja K Natadisastra HA. Anti-mullerian hormone as a diagnostic and prognostic tool for PCOS patients. J Assist Reprod Genet. 2014;31:1311-6.

23. Niodromiti S, Kelsey TW, Anderson RA, Nelson SM. Can anti-Mullerian hormone predict the diagnosis of polycystic ovary syndrome review and meta-analysis of extracted data. J Clin Endocrinol Metab. 2013;98:3332-40.

24. Hart R, Doherty DA, Norman RJ, Franks S, Dickinson JE, Hickey M, Sloboda DM. Serum antimullerian hormone (AMH) levels elevated in adolescent girls with polycystic ovaries and the polycystic ovarian syndrome (PCOS). Fertil Steril. 2010;94:1118-21.

25. Kim JY, Tfayli H, Michaliszyn SF, Lee S, Nasr A, Arslanian S. Anti-Mullerian hormone in obese adolescent girls with polycystic ovary syndrome. J Adol Health. 2016;60:333-9.

26. Thys-Jacobs S, Donovan D, Papadopoulos A, SArrel P, Bilezikian JP. Vitamin $D$ and calcium dysregulation in the polycystic ovarian syndrome. Steroids. 1999:64:430-5.

27. Bacopoulou F, Kolias E, Efthymiou V, Antonopoulos CN, Charmandari E. Vitamin D predictors in polycystic ovary syndrome: a meta-analysis. Eur J Clin Investig. 2017;47:746-55.

28. Butts SF, Seifer DB, Koelper N, Senapati S, Sammel MD, Hoofnagle AN, Kelly A, Krawetz SA, Santoro N, Zhang H, Diamond MP, Legro RS. Vitamin D deficiency is associated with poor ovarian stimulation outcome in PCOS but not unexplained infertility. J Clin Endocrinol Metab. 2019;104:369-78.

29. Selimoglu H, Duran C, Kiyici S, Ersoy C, Guclu M, Ozkaya G, Tuncel E, Erturk $E$, Imamoglu $S$. The effect of vitamin D replacement therapy on insulin resistance and androgen levels in women with polycystic ovary syndrome. J Endocrinol Investig. 2010;33:234-8.

30. Pal L, Berry A, Coraluzzi L, Justan E, Danton C, Shaw J, Taylor H. Therapeutic implications of vitamin $D$ and calcium in overweight women with polycystic ovary syndrome. Gynecol Endocrinol. 2012;28:965-8.

31. Irani M, Seifer DB, Grazi RV, Julka N, Bhatt D, Kalgi B, Irani S, Tal O, LambertMesserlian G, Tal R. Vitamin D supplementation decreased TGF- $\beta 1$ bioavailability in PCOS: a randomized placebo-controlled trial. J Clin Endocrinol Metab. 2015;100:4307-14.

32. Irani M, Seifer DB, Grazi RV, Irani S, Rosenwaks Z, Tal R. Vitamin D decreases serum VEGF correlating with clinical improvement in vitamin D-deficient women with PCOS: a randomized placebo-controlled trial. Nutrients. 2017;9: 334-42.

33. Jafari-Sfidvajani S, Ahangari R, Hozoori M, Mozaffari-Khosravi H, Fallahzadeh $H$, Nadjarzadeh A. The effect of vitamin D supplementation in combination with low-calorie diet on anthropometric indices and androgen hormones in women with polycystic ovary syndrome: a double-blind, randomized, placebo-controlled trial. J Endocrinol Investig. 2018;41:597-607.

34. Javed Z, Papageorgiou M, Deshmukh H, Kilpatrick ES, Mann V, Corless L, Abouda G, Rigby AS, Atkin SL, Sathyapalan T. A randomized, controlled trial of vitamin D supplementation on cardiovascular risk factors, hormones, and liver markers in women with polycystic ovary syndrome. Nutrients. 2019; 11(1):188.

35. Golden NH, Abrams SA, Committee on Nutrition. Optimizing bone health in children and adolescents. Pediatrics. 2014;134:e1229-43.

36. Sadhir M, Kansra AR, Menon S. Vitamin D deficiency among adolescent females with polycystic ovary syndrome. J Pediatr Adolesc Gynecol. 2015;28: 378-81.

37. Bostanci El, Ozler S, Yilmaz NK, Yesilyurt H. Serum 25-hydroxy vitamin D levels in Turkish adolescent girls with polycystic ovary syndrome and the correlation with clinical/biochemical parameters. J Pediatr Adolesc Gynecol. 2018;31:270-3.

38. Merhi ZO, Seifer DB, Weedon J, Adeyemi O, Holman S, Anastos K, et al. Circulating vitamin $D$ correlates with serum antimullerian hormone levels in late-reproductive-aged women: Women's interagency HIV study. Fertil Steril. 2012;98:228-34

39. Wojtusik J, Johnson PA. Vitamin D regulated anti-Mullerian hormone expression in granulosa cells of the hen. Biol Reprod. 2012;86(3):91.

40. Xu J, Lawson MS, Xu F, Du Y, Tkachenko OY, Bishop CV, et al. Vitamin D3 regulates follicular development and intrafollicular vitamin $D$ biosynthesis and signaling in the primate ovary. Front Physiol. 2018;9:1600.

41. Szafarowska M, Dziech E, Kaleata B, Kniotek M, Rogowski A, Segiet-Swiecicka A, Jerzak M. Anti-mullerian hormone level is associated with vitamin D receptor polymorphisms in women with polycystic ovary syndrome. J Assist Reprod Genet. 2019:36(6):1281-9.

42. Davis J, Merhi Z, Berk TS, Neal-Perry G. Developmental vitamin D3 deficiency differentially affects ovarian gene expression patterns in adult female mice. Fertil Steril. 2012;98:S32.

43. Malloy PJ, Peng L, Wang J, Feldman D. Interaction of the vitamin D receptor with a vitamin D response element in the Mullerian-inhibiting substance (MIS) promoter: regulation of MIS expression by calcitriol in prostate cancer cells. Endocrinology. 2009;150:1580-7.

44. Wong HYQ, Li HWR, Lam KSL, Tam S, Shek CC, Lee CYV, et al. Independent association of vitamin D with anti-Mullerian hormone levels in women with polycystic ovary syndrome. Clin Endocrinol. 2018;89:634-41.

45. Cappy H, Giacobini P, Pigny P, Bruyneel A, Leroy-Billard M, Dewally D, Catteau-Jonard S. Low vitamin D3 and high anti-Mullerian hormone serum levels in the polycystic ovary syndrome (PCOS): is there a link? Ann Endocrinol. 2016;77(5):593-9.

46. Ibañez L, Oberfield SE, Witchel S, Auchus RJ, Chang RJ, Codner E, Dabadghao P, et al. An international consortium update: pathophysiology, diagnosis, and treatment of polycystic ovarian syndrome in adolescence. Horm Res Paediatr. 2017;88:371-95

47. Yang Y, Rogers K, Wardle R, El-Khoury JM. High-throughput measurement of 25-hydroxyvitamin D by LC-MS/MS with separation of the C3-epimer interference for pediatric populations. Clin Chim Acta. 2016:454:102-6.

48. Jonard S, Robert Y, Dewailly D. Revisiting the ovarian volume criterion for polycystic ovarian syndrome. Hum Reprod. 2005;20:2893-8.

49. Savas-Erdeve S, Keskin M, Sagsak E, Cenesiz F, Cetinkaya S, Aycan Z. Do the anti-Müllerian hormone levels of adolescents with polycystic ovary syndrome, those who are at risk for developing polycystic ovary syndrome, and those who exhibit isolated Oligomenorrhea differ from those of adolescents with Normal menstrual cycles? Horm Res Paediatr. 2016;85(6):406-11.

50. Bleil ME, Gregorich SE, Adler NE, Stermfeld B, Rosen MP, Cedars MI. Race/ ethnic disparities in reproductive age: an examination of ovarian reserve estimates across four race/ethnic groups of healthy, regularly cycling women. Fertil Steril. 2014:101:199-207.

51. Seifer DB, Golub ET, Lambert-Messerlian G, Benning L, Anastos K, Watts DH, Cohen MH, Karim R, Young MA, Minkoff H, Greenblatt RM. Variations in serum Mullerian inhibiting substance between white, black, and Hispanic women. Fertil Steril. 2009:92:1674-8.

52. Luborsky JL, Meyer P, Sowers MF, Gold EB, Santoro N. Premature menopause in a multi-ethnic population study of the menopause transition. Hum Reprod. 2003;18:199-206.

53. Randolph JF, Sowers M, Gold EB, Mohr BA, Luborsky J, Santoro N, McConnell DS, Finkelstein JS, Korenman SG, Matthews KA, Sternfeld B, 
Lasley BL. Reproductive hormones in the early menopausal transition: relationship to ethnicity, body size, and menopausal status. J Clin Endocrinol Metab. 2003;88:1516-22.

54. Kocaay P, Siklar Z, Buyukfirat S. The diagnostic value of anti-Müllerian hormone in early post menarche adolescent girls with polycystic ovarian syndrome. J Pediatr Adolesc Gynecol. 2018;31:362-6.

55. Rosen MW, Tasset J, Kobernik EK, Smith YR, Johnston C, Quint EH. Risk factors for endometrial cancer or hyperplasia in adolescents and women 25 years old or younger. J Pediatr Adolesc Gynecol. 2019;35:546-9.

\section{Publisher's Note}

Springer Nature remains neutral with regard to jurisdictional claims in published maps and institutional affiliations.

Ready to submit your research? Choose BMC and benefit from:

- fast, convenient online submission

- thorough peer review by experienced researchers in your field

- rapid publication on acceptance

- support for research data, including large and complex data types

- gold Open Access which fosters wider collaboration and increased citations

- maximum visibility for your research: over $100 \mathrm{M}$ website views per year

At BMC, research is always in progress.

Learn more biomedcentral.com/submissions 